\title{
Increased prevalence and incidence of anemia among adults in transforming rural China: two cross-sectional surveys
}

\author{
Xuecai Wang ${ }^{1 \dagger}$, Zhaofan $\mathrm{Wu}^{2 \dagger}$, Yue Chen ${ }^{3}$, Jianfu Zhu' ${ }^{1}$, Xiaolian Dong ${ }^{1}$, Chaowei Fu ${ }^{2 *}$ and Qingwu Jiang ${ }^{2}$
}

\begin{abstract}
Background: Anemia remains one of the serious nutrition-related diseases in China, but data on incidence of anemia were less available, especially in rural area which are experiencing rapid urbanization. Out study aimed to estimate both the prevalence and incidence of anemia in transforming rural China.

Methods: We conducted a combined study of rural adults 18-64 years of age with a repeated cross-sectional component (4456 in 2006 and 2184 in 2008) and a cohort component (1424) in rural Deqing, China. Anemia was diagnosed based on blood hemoglobin levels using the hemiglobincyanide (HiCN) method according to both the World Health Organization (WHO) and Chinese criteria. The prevalence and incidence of anemia and their $95 \%$ confidential intervals (95\% Cl) were calculated.
\end{abstract}

Results: The prevalence of anemia based on the WHO criteria was $51.5 \%$ in 2006 and $53.7 \%$ in 2008, and the 2-year cumulative incidence was $42.1 \%$. Of the cases, over $95 \%$ had mild anemia. The prevalence was much lower when the Chinese criteria was used. Both the prevalence and incidence were higher in women than in men and significantly increased with age in men. In both sexes, the incidence sharply increased after 45 years of age.

Conclusion: Our study showed a high prevalence and incidence of anemia among adults in rural Deging, China. Monitoring and intervention were needed urgently, especially among individuals over 45 years of age.

Keywords: Anemia, Prevalence, Incidence, Rural China

\section{Background}

Anemia is one of the serious nutrition-related diseases, which is associated with increased morbidity and mortality, and can lead to cardiovascular and neurological events $[1,2]$. The World Health Organization (WHO) estimated that 1.62 billion people worldwide were affected by anemia in the period of 1993-2005, which corresponds to $24.8 \%$ of the population, and most of them were in developing countries including China [3, 4]. A nationwide survey conducted in China indicated that $20.1 \%$ of residents were affected by anemia in $2002[5,6]$.

Since early 1980s, China had been experiencing great changes in nutrition, health care and aging, which were

\footnotetext{
* Correspondence: cwfu@shmu.edu.cn

${ }^{\dagger}$ Equal contributors

${ }^{2}$ Department of Epidemiology, School of Public Health and Key Laboratory of Public Health Safety, Fudan University, 138 Yi Xue Yuan Road, Shanghai 200032, China

Full list of author information is available at the end of the article
}

associated with the occurrence of anemia; however, few surveys studied the changes in the prevalence and incidence of anemia [7-9]; especially in transforming rural China [10-12] . One difficulty was that there were two different diagnostic criteria for anemia used in China: WHO and Chinese $(\mathrm{CN})$ criteria. The WHO criteria [3] was generally accepted for public health research and $\mathrm{CN}$ one was commonly used in clinical diagnosis [13] . The difference in the estimation of prevalence and incidence between the two criteria in Chinese population and to what extent had rarely been studied so far.

Deqing County is one of the most developed areas in China [14], and has been experiencing rapid urbanization. This study was carried out to estimate the prevalence and its change over a 2-year period, and the incidence of anemia. We also compared the estimates for anemia occurrence using the $\mathrm{WHO}$ and Chinese criteria. 


\section{Methods}

\section{Study population}

A combined study with a repeated cross-sectional component and a cohort component was conducted in rural Deqing County, Zhejiang Province, China. A total of 5898 participants were randomly cluster-sampled from three rural communities (Nanlu, Wukang and Zhongguan) in 2006 [15] and 4456 (76\%) of them had hemoglobin measurement. A repeated cross-sectional study was carried out in the largest community (Nanlu) of these three rural communities in 2008 and 2975 subjects were recruited with 2184 subjects having hemoglobin measurement. Of 2211 subjects who participated the 2006 survery in Nanlu Community, 1424 (577 had anemia and 847 had no anemia in 2006) were followed up in 2008 (Fig. 1).

Inclusion criteria of subjects were those who 1) were aged 18-64 years old; 2) were local residents living for more than 6 months during the past 12 months in those rural communities; 3 ) provided written informed consent; and 4) answered the questions independently. Temporary workers or students living in the communities for no more than 6 months during the past 12 months were excluded from the study.

\section{Data collection}

Local health workers who were recruited and trained by academic investigators, conducted face-to-face interviews. A questionnaire covered the information on demographic factirs (including birthday, gender, marriage, education years, occupation, family size, family incoming, and so on) and behavioral factors (including smoking, alcohol drinking, tea drinking, diet and physical exercise). For those who had fasted for more than $8 \mathrm{~h}$, physical examinations were carried out including height, weight, wais circumference, heart rate, blood pressure, electrocardiogram and type-B ultrasonic. Venous blood of $5 \mathrm{ml}$ were collected and preserved under $-20{ }^{\circ} \mathrm{C}$ with and without anticoagulant. Hemoglobin was measured within $24 \mathrm{~h}$ after collecting blood using the hemiglobincyanide ( $\mathrm{HiCN})$ method.

\section{Definition of anemia}

Anemia was diagnosed based on blood hemoglobin levels using both the WHO criteria (hemoglobin $<130 \mathrm{~g} / \mathrm{L}$ for men or $<120 \mathrm{~g} / \mathrm{L}$ for women and $90 \mathrm{~g} / \mathrm{L}<$ hemoglobin $<130 \mathrm{~g} / \mathrm{L}$ for men or $90 \mathrm{~g} / \mathrm{L}<$ hemoglobin $<120 \mathrm{~g} / \mathrm{L}$ for women as mild anemia) and the Chinese criteria (hemoglobin $<120 \mathrm{~g} / \mathrm{L}$ for men or $<110 \mathrm{~g} / \mathrm{L}$ for women) $[3,16]$.

\section{Data analysis}

All statistical tests were performed using SPSS17.0 (SPSS Inc, Chicago, Illinois, USA). For comparison, Chi-square test was used for categorical variables, and independent $t$ test for continuous variables. The prevalence and cumulative incidence of anemia and their $95 \%$ confidential intervals $(95 \% \mathrm{CI})$ were calculated. An alpha level of $<0.05$ (two sides) was considered to be statistically significant.

\section{Results}

The 2006 survey included 4456 participants with hemoglobin measured and the 2008 survey included

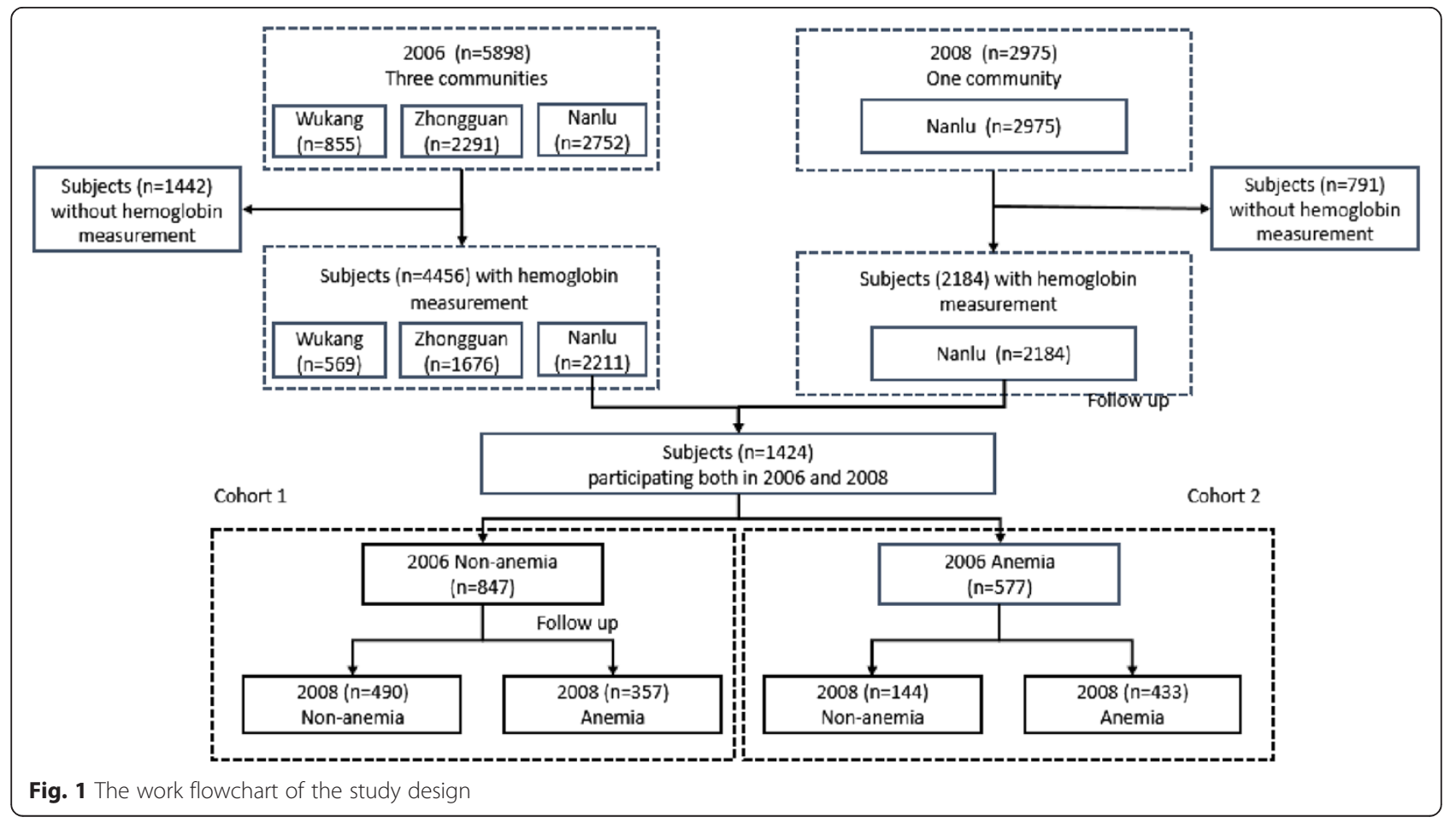


2184. Participants in the two cross-sectional studies had similar average age and BMI and similar distributions of gender, education level and physical exercise $(p>0.05)$. However, the study population had higher proportions of low-income families, famers, smokers, drinkers and mainly vegetable eaters for the 2008 survey compared with the 2006 survey $(p<0.001)$ (Table 1$)$.

Mean hemoglobin levels were $123.5 \pm 19.3 \mathrm{~g} / \mathrm{L}$ in 2006 similar to that of $123.3 \pm 16.7 \mathrm{~g} / \mathrm{L}$ in $2008(\mathrm{t}=$ $0.49, P=0.626)$. According to the WHO criteria, the prevalence of anemia was $51.5 \%$ (95 \% CI: $50.0-$ $52.9 \%$ ) in 2006 and $53.7 \%$ (95 \% CI: $51.6-55.8 \%$ ) in 2008. Over $95 \%$ of the patients were considered to

Table 1 Characteristics of participants in 2006 and 2008

\begin{tabular}{|c|c|c|c|}
\hline & $2006(n=4456)$ & $2008(n=2184)$ & \\
\hline & $\begin{array}{l}\text { Mean } \pm \\
\text { Deviation }\end{array}$ & $\begin{array}{l}\text { Mean } \pm \\
\text { Deviation }\end{array}$ & $x 2, p$ value \\
\hline Age (years) & $46.8 \pm 9.5$ & $46.8 \pm 9.4$ & $0.1,0.952$ \\
\hline BMI (kg/m2) & $22.1 \pm 3.7$ & $22.1 \pm 3.9$ & $0.2,0.847$ \\
\hline & No.[\%] & No.[\%] & $\mathrm{t}, p$ value \\
\hline Gender & & & $1.8,0.175$ \\
\hline Men & $1846[41.4]$ & $943[43.2]$ & \\
\hline Women & $2610[58.6]$ & $1241[56.8]$ & \\
\hline Education & & & $3.6,0.057$ \\
\hline Middle school or above & $1703[38.4]$ & 887 [40.8] & \\
\hline Below middle school & $2731[61.6]$ & 1285 [59.2] & \\
\hline $\begin{array}{l}\text { Household } \\
\text { income level }\end{array}$ & & & $49.5,<0.001$ \\
\hline Low & $492[11.1]$ & $377[17.3]$ & \\
\hline Medium & 3314 [74.6] & $1514[69.4]$ & \\
\hline High & $634[14.3]$ & 289 [13.3] & \\
\hline Occupation & & & $53.3,<0.001$ \\
\hline Famer & 3206 [72.4] & $1753[80.7]$ & \\
\hline Non-famer & $1222[27.6]$ & 420 [19.3] & \\
\hline Smoking & & & $11.7,<0.001$ \\
\hline Yes & $1227[27.6]$ & $690[31.7]$ & \\
\hline NO & $3216[72.4]$ & 1489 [68.3] & \\
\hline Alcohol use & & & $17.3,<0.001$ \\
\hline Yes & 938 [21.1] & $559[25.6]$ & \\
\hline NO & 3518 [78.9] & $1625[74.4]$ & \\
\hline Physical exercise & & & $2.4,0.125$ \\
\hline Yes & $93[2.2]$ & $59[2.8]$ & \\
\hline NO & $4125[97.8]$ & 2022 [97.2] & \\
\hline $\begin{array}{l}\text { Dietary chief } \\
\text { component }\end{array}$ & & & $18.7,<0.001$ \\
\hline Vegetable & $622[14.0]$ & 391 [18.0] & \\
\hline Meat & $314[7.1]$ & $160[7.4]$ & \\
\hline Vegetable and Meat & 3493 [78.9] & 1617 [74.6] & \\
\hline
\end{tabular}

have mild anemia. In the follow-up study of 847 participants without anemia in 2006, the 2-year cumulative incidence of anemia was $42.1 \%$ (95 \% CI: 38.8-45.5\%). Also, 577 subjects with anemia in 2006 were followed up, and 24.9 \% (95 \% CI: 21.4-28.5 \%) of them recovered from anemia in 2008. When the Chinese criteria was used, the prevalence and 2-year cumulative incidence of anemia were 24.5 and $22.1 \%$, respectively (Tables 2 and 3 ).

The prevalence and 2-year cumulative incidence of anemia were both significantly higher among women than men in all age groups, and the difference gradually narrowed as age rose. The 2-year cumulative incidence increased significantly with age in men, while it was the highest in the 18-34-year age group, then dropped slightly in the 35-44-year age group and gradually increased again after 45 years of age in women. In both sexes, the incidence sharply increased after 45 years of age (Tables 2 and 3).

\section{Discussion}

In the current study, about half of the study population had anemia in Deqing, which was far higher than the estimates from previous studies, such as $16.2 \%$ in rural China in 2002 [17], $18.9 \%$ in Zhejiang province, China in 2005 [18], $17.1 \%$ in Japan [19] and $24.8 \%$ for the global population [4] . Some limited epidemiologic data on the incidence of anemia among general populations [8] revealed that the incidence in elderly was 24.0 per 1000 personyears in Korea [9], 24.2 per 1000 person-years in Italy [8] and 5.8 per 1000 person-years in Germany [7]. Compared with these results, the incidence (approximately 220 per 1000 person-years) in the present study was extremely high. Several reasons may explaine the high incidence. 1) Data from the Fourth China Health and Nutrition Survey demonstrated that hemoglobin levels among Chinese were lower than those from other countries in general [13]. 2) In rural Deqing, meat that contains high iron accounts for small proportions of local diet. We found that subjects who had vegetable and meat evenly, had a lower risk of anemia than those having vegetable mainly, after adjustment for age, gender, education, income and BMI. 3) In the current study, although about a half of subjects were anemic, most of them had mild anemia which is considered to have a minimal effect on health. One-fourth of patients recovered form anemia without any treatment over a 2-year period.

Rural areas of China have been undergoing a rapid urbanization during the past several decades. In one way, as family income increases, there is an changing pattern of diet. It is obaserved that more energy rather than nutrition has been taken among some Chinese residents [20], which may not help in improving their nutrition status overall. In another way, a larger proportion of participants, especially 
Table 2 Prevalence of anemia (\%) according to WHO and Chinese criteria among adults in rural Deqing

\begin{tabular}{|c|c|c|c|c|c|c|}
\hline \multicolumn{7}{|l|}{ WHO criteria } \\
\hline \multirow[t]{2}{*}{ Age (years) } & \multicolumn{3}{|c|}{$2006(n=4456)$} & \multicolumn{3}{|c|}{$2008(n=2184)$} \\
\hline & Men & Women & Total & Men & Women & Total \\
\hline $18-34^{a}$ & $38(20.5)$ & 196(63.4) & 234(47.4) & 12(19.4) & 79(73.8) & $91(53.8)$ \\
\hline $35-44$ & $169(29.5)$ & $571(64.7)$ & $740(50.8)$ & $64(25.7)$ & 232(64.8) & $296(48.8)$ \\
\hline $45-54$ & 232(35.9) & $525(61.7)$ & $757(50.5)$ & 155(40.8) & 287(64.8) & $442(53.7)$ \\
\hline $55-64$ & 199(45.1) & $364(64.2)$ & $563(55.9)$ & $120(45.5)$ & 218(70.6) & $338(59.1)$ \\
\hline Total & 638(34.6) & $1656(63.4)$ & 2294(51.5) & $351(36.8)$ & $816(67.1)$ & $1167(53.7)$ \\
\hline$x 2, p$ & $44.8,<0.001$ & $1.8,0.67$ & $11.8,0.008$ & $36.1,<0.001$ & $7.2,0.67$ & $14.1,0.003$ \\
\hline$X^{2}$ trend, $\mathrm{P}$ & $45.6,<0.001$ & $1.83,0.61$ & $8.9,0.003$ & $37.9,<0.001$ & $7.3,0.62$ & $14.2,0.003$ \\
\hline \multicolumn{7}{|c|}{ Chinese criteria } \\
\hline $18-34^{a}$ & $9(4.9)$ & 108(35.0) & $117(23.7)$ & $4(6.5)$ & 47(43.9) & $51(30.2)$ \\
\hline $35-44$ & $53(9.2)$ & $321(36.4)$ & $374(25.7)$ & $18(7.2)$ & $116(32.4)$ & $134(22.1)$ \\
\hline $45-54$ & 77(11.9) & 281(33.0) & $358(23.9)$ & $62(16.3)$ & 132(29.8) & 194(23.6) \\
\hline $55-64$ & $96(21.8)$ & 214(37.7) & $310(30.8)$ & $46(17.4)$ & 107(34.6) & 153(26.7) \\
\hline Total & $235(12.7)$ & $924(35.4)$ & $1159(26.0)$ & 130(13.6) & $402(33.1)$ & $532(24.5)$ \\
\hline$x 2, p$ & $49.4,<0.001$ & $3.8,0.28$ & $16.7,0.001$ & $17.5,0.001$ & $12.0,0.007$ & $9.0,0.300$ \\
\hline$X^{2}$ trend, $p$ & $47.9,<0.001$ & $3.9,0.28$ & $16.4,0.001$ & $19.4,<0.001$ & $11.6,0.009$ & $8.7,0.033$ \\
\hline
\end{tabular}

${ }^{\mathrm{a}} 18-24$ and $25-34$ year age groups were combined due to small sizes

older people and women, mainly consumed vegetables. This may be one reason for the observation that more than $40 \%$ develped anemia but only one quarter recovered from anemia during two-year period in this study.

The Fourth China Health and Nutrition Survey showed that the quartile range of hemoglobin in Chinese was lower than those from other countries [13]. Because the cut-off points for anemia for the $\mathrm{CN}$ criteria, regardless of gender, were $10 \mathrm{~g} / \mathrm{L}$ lower than those for the WHO criteria (WHO vs CN: 130 vs $120 \mathrm{~g} / \mathrm{L}$ for men; 120 vs $110 \mathrm{~g} / \mathrm{L}$ for women) $[3,16]$. The $10 \mathrm{~g} / \mathrm{L}$ difference between the two criteria has made huge differences in the estimation of both prevalence and incidence since about half of patients with anemia based on the WHO criteria in rural Deqing had their hemoglobin levels in 120-130 g/L among men and 110$120 \mathrm{~g} / \mathrm{L}$ among women. Anemia is considered to be one of the most serious nutrition-related diseases in China, and more researches should be done to explore health hazards with different criteria of anemia to develop proper cut-off points of anemia for Chinese populaiton.

Our results revealed higher prevalence and incidence of anemia among women than men in all age groups, and the sex differences gradually narrowed as age rose. Iron deficiency can be caused by menstruation, pregnancy and lactation in women, and the impact on the sex difference may diminich with age, especially after menopause [21, 22]. In another aspect, however, the prevalence and incidence anemia increased with age, especially in men, which was consistent with results from a system review [23] and an age dependency of anemia occurrence was also found in a longitudinal Swedish study [24] . For both sex, we observed a relatively higher prevalence and incidence among those 45 years of age

Table 3 Cumulative incidence of anemia (\%) according to WHO and Chinese criteria among adults in rural Deqing

\begin{tabular}{|c|c|c|c|c|c|c|}
\hline \multirow[t]{2}{*}{ Age(years) } & \multicolumn{2}{|l|}{ Men } & \multicolumn{2}{|l|}{ Women } & \multicolumn{2}{|l|}{ Total } \\
\hline & $\overline{\mathrm{WHO}}$ & $\mathrm{CN}$ & $\overline{\mathrm{WHO}}$ & $\mathrm{CN}$ & $\overline{\mathrm{WHO}}$ & $\mathrm{CN}$ \\
\hline 18-34 & $4(13.3)$ & $3(8.3)$ & $27(67.5)$ & 21(35.1) & $31(44.3)$ & $24(25.1)$ \\
\hline $35-44$ & $32(23.2)$ & $21(12.4)$ & $67(50.0)$ & $51(23.4)$ & $99(36.4)$ & $72(18.6)$ \\
\hline $45-54$ & $54(32.3)$ & $22(10.5)$ & $84(56.0)$ & $56(25.7)$ & 138(43.5) & 78(18.2) \\
\hline $55-64$ & $35(36.8)$ & 19(16.2) & $54(58.1)$ & $36(27.3)$ & $89(47.3)$ & $55(22.1)$ \\
\hline Total & $125(29.1)$ & $65(12.2)$ & 232(55.6) & $164(26.1)$ & $357(42.1)$ & $229(19.7)$ \\
\hline$x 2, p$ & $9.6,0.023$ & $2.9,0.412$ & $4.2,0.247$ & $3.4,0.334$ & $6.1,0.105$ & $3.5,0.324$ \\
\hline$X 2_{\text {trend, }} \mathrm{P}$ & $10.1,0.018$ & $2.8,0.422$ & $4.3,0.232$ & $3.3,0.351$ & $6.2,0.103$ & $3.4,0.338$ \\
\hline
\end{tabular}

CN Chinese criteria 
or older, and previous studies from Korea and the United State used age cutpoint of 49 years and found similar results $[25,26]$. Older adults were found to have lower levels of hemoglobin and hematocrit than younger adults because of decreasing physiological functions and studies suggested to use the hemoglobin level of $<110 \mathrm{~g} / \mathrm{L}$ as the diagnostic criteria for older adults [27, 28]. Our finding indicated that the age of 45 years may be an important age point for the prevention of anemia for rural Chinese,

The findings of our study should be considered with awareness of its limitations. First, only a portion $(64.4 \%)$ of the subjects were followed up, who were slightly older, more likely to be woman, having lower education than those who were not followed up (Additional file 1: Table S1), which might result in an overestimated incidence. Secondly, although all blood were tested with the same method and equipment at the Deqing Center for Disease Control, measurement errors might exit and vary. However, we have no reason to believe that there exit a systematic error for the observed high prevalence and incidence in the context that such equipment was evaluated and adjusted every year in a national center for laboratory equipment and testing, which was done under a standard operation procedure. Thirdly, the study population was from more developed rural area of China, and therefore extra caution should be taken when the findings from this study are generalized to more broader populations with different socioeconomic status. In addition, there may be some impacts from unmeasured factors such as vitamin B12 and genetic variants, and for repeated surveys, part of the anemia variation might be due to the regression towards mean.

\section{Conclusion}

In conclusion, anemia was prevalent among the community population aged 18-64 years in rural Deqing, which calls for interventions, especially for those aged 45 years old or above. The WHO and Chinese criteria for anemia showed marked differences in the estimation of prevalence and incidence for this rural population. More researches are needed to explore health hazards associated with different criteria of anemia and to develop proper cut-off points of hemoglobin for anemia diagnosis in Chinese populaiton.

\section{Ethics approval}

The study was approved by the Institutional Review Board of the Fudan University School of Public Health. A written informed consent was obtained after a complete description of the study narrated to each subject.

\section{Additional file}

Additional file 1: Table S1: Comparison of characteristics between participants followed up and those not. (DOC $46 \mathrm{~kb}$ )

\section{Abbreviations}

HiCN: hemiglobincyanide; WHO: World Health Organization; CN: Chinese criteria; BMI: Body Mass Index; CDC: Center for Disease Control.

\section{Competing interests}

The authors declare that they have no competing interests.

\section{Author's contributions}

WXC participated in the design of the study and carried out the prospective studies. WZF performed the statistical analysis and drafted the manuscript. ZJF and DXL participated in the design, coordination and data collection. FCW,YC and JQW participated in its designing, carrying out and revised the manuscript critically. All authors read and approved the final manuscript.

\section{Acknowledgement}

The authors would like to give their thanks to the health workers of the Deqing County Centre of Disease Prevention and Control and the community health centers for data collection.

\section{Funding}

This study was supported by Fudan Graduate Innovation Foundation (grant number EYF201019), National Natural Science Foundation of China (Project Number: 81473038) and Shanghai Leading Academic Discipline Project of Public Health (Project Number: 12GWZX0101)

\section{Author details}

${ }^{1}$ Deqing County Center of Disease Prevention and Control, Deqing, Zhejiang Province, China. ${ }^{2}$ Department of Epidemiology, School of Public Health and Key Laboratory of Public Health Safety, Fudan University, 138 Yi Xue Yuan Road, Shanghai 200032, China. ${ }^{3}$ Faculty of Medicine, University of Ottawa, Ottawa, Ontario, Canada.

Received: 2 June 2015 Accepted: 21 December 2015

Published online: 28 December 2015

\section{References}

1. Penninx BW, Pahor M, Woodman RC, Guralnik JM. Anemia in old age is associated with increased mortality and hospitalization[J]. J Gerontol A-Biol. 2006;61(5):474-9.

2. Culleton B-F, Manns B-J, Zhang J, Klarenbach S, Hemmelgarn BR. Impact of anemia on hospitalization and mortality in older adults[J]. Blood. 2006; 107(10):3841-6.

3. Iron deficiency anaemia assessment, prevention and control[R]. Geneva: World Health Organization, 2008.http://www.who.int/nutrition/publications/ en/ida_assessment_prevention_control.pdf. [Accessed on Dec. 24, 2015]

4. Erin ML, Mary C, Ines E, Wojdyla D, de Benoist B. Worldwide prevalence of anaemia, WHO Vitamin and Mineral Nutrition Information System, 1993-2005[J]. Public Health Nutr. 2009;12(4):444-54.

5. Piao J-H, Lai JQ, Yin SA, Xu J, Xu Q-M, Yang X-G. Study on the anemia status of Chinese population[J]. Acta Nutrimenta Sinica. 2005;04:268-75. In Chinese.

6. Chang S-Y, Ge K-Y. Factor associated with nutrition in Chinese adult[J]. Acta Nutrimenta Sinica. 1998:20(2):132-7 (In Chinese).

7. Eisele L, Durig J, Broecker-Preuss M, Dührsen U, Bokhof B, Erbel R, et al. Prevalence and incidence of anemia in the German Heinz Nixdorf Recall Study[J]. Ann Hematol. 2013;92(6):731-7.

8. Tettamanti M, Lucca U, Gandini F, Recchia A, Mosconi P, Apolone G, et al. Prevalence, incidence and types of mild anemia in the elderly: the "Health and Anemia" population-based study[J]. Haematologica. 2010;95(11):1849-56.

9. Choi C-W, Lee J, Park K-H, Choi IK, Kim SJ, Seo JH, et al. Incidence of anemia in older Koreans: community-based cohort study[J]. Arch Gerontol Geriatr. 2005:41(3):303-9.

10. Yang W, Li X, Li Y, Zhang S, Liu L, Wang X, et al. Anemia, malnutrition and their correlations with socio-demographic characteristics and feeding practices among infants aged 0-18 months in rural areas of Shaanxi 
province in northwestern China: a cross-sectional study[]]. BMC Public Health. 2012;12(1):1127.

11. Mahoney Jr D-H. Anemia in at-risk populations-what should be our focus?[J]. Am J Clin Nutr. 2008;88(6):1457-8.

12. Shi Z, Zhen S, Wittert G-A, Yuan B, Zuo H, Taylor AW. Inadequate riboflavin intake and anemia risk in a Chinese population: five-year follow up of the Jiangsu Nutrition Study[J]. PLoS One. 2014;9(2):e88862.

13. Junsheng $\mathrm{H}$. Exploration of anemia diagnostic criteria[]]. China Health Stand Manage. 2010;1:34-6.

14. Zhejiang Statistical Yearbook 2014[R]. Beijing: Zhejiang Provincial Bureau of Statistics, 2014[2015-11-03 17:00:00] (In Chinese)

15. Fu C, Chen Y, Wang F, Wang X, Song J, Jiang Q. High prevalence of hyperglycaemia and the impact of high household income in transforming rural China[J]. BMC Public Health. 2011;11:862.

16. Lu ZY, Zhong N-S. Anemia. Internal Medicine. 2nd ed. Beijing: People's Medical Publishing House; 2008. In Chinese.

17. Li L, Rao K, Kong L. A description on the Chinese national nutrition and health survey in 2002[J]. Chin J Epidemiol. 2005;26:478-84 (In Chinese).

18. Liu L-q, Yu M, Zhong J-m. A survey on the nutrition and health status of residents in Zhejiang Province [J]. Zhejiang Prev Med. 2007;19:1-3 (In Chinese).

19. Tsujioka T, Tohyama K. Prevalence of anemia in Japan][J. Nihon Rinsho. 2008:66(3):429-32.

20. Du S, Mroz T-A, Zhai F, Popkin BM. Rapid income growth adversely affects diet quality in China-particularly for the poor![]]. Soc Sci Med. 2004:59(7):1505-15.

21. Coad J, Conlon C. Iron deficiency in women: assessment, causes and consequences[J]. Curr Opin Clin Nutr Metab Care. 2011;14(6):625-34.

22. Hin H, Lehman R, Bird G. Iron-deficiency anaemia in premenopausal women[J]. Lancet. 1999:353(9157):1015-6.

23. Gaskell H, Derry S, Andrew M-R, McQuay HJ. Prevalence of anaemia in older persons: systematic review[]]. BMC Geriatr. 2008;8:1.

24. Martinsson A, Andersson C, Andell P, Koul S, Engström G, Smith JG. Anemia in the general population: prevalence, clinical correlates and prognostic impact[]]. Eur J Epidemiol. 2014;29(7):489-98.

25. Lee J-O, Lee J-H, Soyeon A, Kim JW, Chang H, Kim YJ, et al. Prevalence and risk factors for iron deficiency anemia in the Korean population: results of the fifth Korea National Health and nutrition examination survey[]]. J Korean Med Sci. 2014;29(2):224.

26. Guralnik J-M, Eisenstaedt R-S, Ferrucci L, Klein HG, Woodman RC. Prevalence of anemia in persons 65 years and older in the United States: evidence for a high rate of unexplained anemia[J]. Blood. 2004;104(8):2263-8.

27. Bach V, Schruckmayer G, Sam I, Kemmler G, Stauder R. Prevalence and possible causes of anemia in the elderly: a cross-sectional analysis of a large European university hospital cohort[]]. Clin Interv Aging. 2014;9:1 187-96.

28. Zhang C, Peng X-L. Explore of diagnostic criteria for anemia in elderly[J]. J Clin Hematol. 2000;05:217-8 (In Chinese).

\section{Submit your next manuscript to BioMed Central and we will help you at every step:}

- We accept pre-submission inquiries

- Our selector tool helps you to find the most relevant journal

- We provide round the clock customer support

- Convenient online submission

- Thorough peer review

- Inclusion in PubMed and all major indexing services

- Maximum visibility for your research

Submit your manuscript at www.biomedcentral.com/submit

C Biomed Central 